\title{
The structure of lay-concepts within the fear spectrum revealed using emotional verbal fluency
}

\author{
Barbara Gawda ${ }^{1}$ (D) \\ Published online: 30 May 2020 \\ (C) The Author(s) 2020
}

\begin{abstract}
Given the fact that natural language analysis can distinguish constituents of mental constructs, the present research was designed to investigate the structure of concepts related to the broad spectrum of emotions comprising worry, fear, anxiety, and panic, which in this article is referred to as the 'fear spectrum'. A new technique presented here is based on a word association task and enables a description of the structure of emotion concepts. The technique is a variant of a verbal fluency task, i.e. emotional verbal fluency technique. Two studies have been conducted: the first to examine the cognitive structure of concepts within the fear spectrum ( $n=280,150$ women, $130 \mathrm{men}$ ) and the second to confirm the stability of word association in the fear tasks and differentiation of the fear concepts in relation to trait anxiety and dogmatism ( $n=190,100$ women, 90 men). A hierarchical clustering analysis, based on the linguistic material, i.e. words produced by the participants for the task of anxiety, was performed to present in what way the emotional verbal fluency technique can be applied to explore the structure of emotional concepts. According to our results, there is a relatively constant tendency in producing semantic clusters (emotional word association) among lay people. Moreover, produced clusters allow to describe the structure and to differentiate lay-concepts within the fear spectrum, such as worry, fear, anxiety, panic [respectively in Polish: obawa, lęk, strach, panika].
\end{abstract}

Keywords Fear $\cdot$ Emotional concepts $\cdot$ Mental representations, verbal fluency method $\cdot$ Cognitive structure

\section{Introduction}

\section{Emotional Concepts}

Emotional concepts are forms of mental representation of knowledge related to emotions. They belong to natural type concepts which are based on realistic approach and the prototype theory (Eysenck 2012). Unlike classical concepts, natural concepts do not have strict limits and binary attributes. They are not clearly defined, have no clear definitional boundaries, nor a definitional structure. Natural concepts are more or less specific, they depend on experience and situations, being an element of lay-representation of the world. The construction of natural concepts is explained in terms of the theory of fuzzy sets (Fehr 2005; Russell and Bullock 1986). Emotion concepts, according to Niedenthal (2008, p. 587), are "mental representations of

Barbara Gawda

bgawda@wp.pl

1 Department of Psychology of Emotion \& Personality, Institute of Psychology, Maria Curie-Sklodowska University, Plac Litewski 5, 20-080 Lublin, Poland categories, objects, situations, and activities". They contain information about "the causes of emotions, i.e. situational factors potentially causing emotions, behaviors or activities commonly associated with a given emotion, and internal subjective states typical for a given emotion, and its meaning" (Niedenthal 2008, p. 588). It is thought that conceptualization of emotions can be characterized by several properties: rooting in a more general theory of mind, hierarchical organization, typology, relativity of categories, bipolar dimensions in some cases, unfocused boundaries, typology, inter-categorical relationships, associations with scripts and scenarios (Russell and Lemay 2000). Another important viewpoint suggests that the description of natural concepts, including emotional concepts, can be described on the basis of natural i.e. lay language (Wierzbicka 1992a, b). This analysis allows to explore and describe mental representations as concepts because language is part of the mind and simultaneously a force that gives humans shape to mental and social capabilities (Wierzbicka 1992a). Dimensional, semantic units, prototype, and semantic network models are the main four emotional concept model groups (Niedenthal 2008; Niedenthal et al. 2006). There is also a model of script proposed by Russell $(1991,2005)$. It assumes that the structure of an emotional concept, defined as a script, 
comprises key elements portraying emotional events such as: beliefs, causes, desires, sensations, activity, physiological changes, as well as mimic, and vocal expressions. This emotional script is of prototype structure, which means that it contains the most typical/common element of a given emotion. Moreover, there are some emotion concepts with a distinct structure. For instance, a concept that can encompass a list of features or unique items (as it is proposed by the exemplar theory: Kroska and Goldstone 1996). The latest approaches to emotional concepts, applying the construct of semantic network, include the embodied multiple representation models (Andrews et al. 2014; Lenci et al. 2018). These assume that all concepts, including emotional concepts, are constituted by the two main types of information, experiential (such as sensory, motor, and affective) and linguistic (Vigliocco et al. 2013, 2014; Vinson et al. 2014).

The aim of the present research is to show a novel approach to investigating the structure of emotion concepts. The paper focuses specifically on concepts representing the fear spectrum. This project is part of larger research on emotional concept types. Concepts within the fear spectrum are noteworthy because emotions such as fear and anxiety are fundamental in everyday life and clinical situations. Every person often experiences emotions and feelings from this spectrum. We were driven to investigate whether lay people have differentiated emotional concepts of the subtle emotions from the fear group. While scientific theories point to several anxiety types and worry typologies, we aim to show whether lay-people have such a differentiated knowledge on these emotions. At this point, it is necessary to explain the terms used in this paper. Emotional concepts or emotion concepts are types of mental representations indirectly reflecting a person's knowledge about a given emotion. This knowledge can be explored as it is revealed in a series of associations/semantic clusters produced in verbal fluency tasks. Importantly, a semantic cluster consists of at least two words generated in succession and related semantically, e.g. words men, women $=$ cluster 'people'. Emotion words or emotional words are understood as the words which denote emotions (e.g. fear). They are not words with emotional connotations (e.g. a bird). Emotions are mental states encompassing such basic components as bodily/ physiological responses, perceptual (visual or auditory) information, and conceptual knowledge of emotional categories (Barrett 2012, 2013, 2014; Lindquist 2013). Finally, emotional categories are abstract terms naming emotional concepts.

\section{Fear and Emotions within the fear Spectrum}

The emotion of fear is a consequence of the fact that a situation is assessed as threatening. Causes of such a situation may be varied and include physical threat, danger associated with violation of interpersonal relations, as well as more complex forms of insecurity such as disease or job loss; generally these are situations recognized as threatening or posing hazard to human life or well-being (Lazarus 1991). The emotion of fear in psychology is distinguished from the emotion of anxiety, the former being classified as a basic emotion and the latter as a complex emotion (LeDoux 2015). Furthermore, anxiety is considered to be a consequence of an indirect and non-specific threat (Öhman 2008). Barlow (2002) defines anxiety as a vague, unpleasant emotional state characterized by an experience of apprehension, worry, stress and distress. Anxiety arises in one's imagination, as a response to experiences interpreted as a threat. This contributes to a sense of helplessness, powerlessness and insecurity (Zeidner and Matthews 2011). According to many theoreticians, anxiety appears in early childhood and accompanies the individual continuously until the end of life. This is something that exists regardless of the culture, level of personal or national development (Rachman 2004). Changes only occur in the object, the cause which induces anxiety in each case, and - looking at the problem from the other side - in the preventive measures and methods we use to overcome the emotion (Riemann 2009). Therefore, it is recognized as one of the essential, ever-present and all-embracing affects (Rachman 2004). Although fear is classified as one of the so-called basic emotions and anxiety is a complex emotion, they both occur in situations of threat, yet in the case of fear, the danger is of more direct and objective nature, and in the case of anxiety it is more varied and subjective (Izard 1992). The difference between anxiety and fear lies not only in the type of stimulus which induces an emotional response. According to LeDoux (2015) anxiety comes "from the inside", which means it is preceded with a complex cognitive interpretation of the situation. Lazarus (1991) defines anxiety as a group of responses which comprises physiological changes, expressive reactions, the individual's utterances, as well as subjective feelings of tension and insecurity. Furthermore, Barlow (2002) assumes that fear and anxiety comprise subjective cognitive, physiological and behavioral components, anxiety being a mixture of diffuse emotions and thoughts. Anxiety is associated with bad mood, sense of foreboding and lack of ability to predict; it does not trigger a fight response rather preparing for it, although it apparently comprises the same components as fear (Öhman 2008). Izard (1992) believes that anxiety is a combination of a few basic emotions: fear, distress, anger, shame and excitation. According to Dąbrowski (1996) fear/anxiety may take five forms, depending on the level of personality integration/disintegration. At the lowest level, fear results from imminent threat, it is a response to danger and is not accompanied with reflection. At the second level, fear is linked with periodic changes in mood and temporal ambivalence; with attempted self-control it can be directed properly. At the third level, the emotions of fear and anxiety appear in the context of prosocial behaviors, self-criticism, sense of inferiority, shame, guilt, and self-assessment, which leads to the development of self- 
control. At the fourth level, the emotion of fear/anxiety is associated with a development of self-reflection, selfawareness and inner conflicts as well as empathy. Finally, at the fifth level, these emotions are linked with a sense of responsibility, authentic life, and conflicts of philosophical and existential nature (Dąbrowski 1996, pp. 51-55).

The complex structure of anxiety has been emphasized by researchers specializing in clinical psychology and psychiatry. Multifaceted nature of this emotion means that in its structure the feeling of anxiety may contain behavioral (increased activity), and cognitive (compulsive thinking and behaviors), as well as personality and affect related elements (defense mechanisms) (LeDoux 2015). Anxiety is thought to be a specifically human affective feeling, while fear is also experienced by animals (Barlow 2002). Anxiety is a more complex way to respond to a problem, it reflects the capacity for human instinctive reactions and for conducting analysis of multidimensional situations. According to existential psychology, anxiety is a fundamental manifestation and foundation of human existence (May 1950). Researchers focusing on anxiety have pointed out that the emotion takes many forms, therefore it is difficult to define it precisely and to classify types of anxiety (Kępiński 2009). Nevertheless, some highly valuable attempts have been made to create a typology of anxiety. The criteria on which such typology can be based include the area or the object related to anxiety. Hence, among the possible types of anxiety we can find: biological (result of being threatened), social (resulting from condemnation by a group of people), moral (resulting from transgression or breach of ethical norms) as well as disintegrative (appearing as a result of any violation of fixed structure of interaction with environment) (Kępiński 2009). Biological anxiety is closely linked with an experience of physical suffering and pain; it is a sense of foreboding related to physical suffering, or negative sensations due to illness, bodily injury or other pain inducing factors. On the other hand, social anxiety is linked with exposition. One of its forms is shyness. It is characterized by high activation of the autonomic nervous system during social interactions, a sense of awkwardness and discomfort, which leads to withdrawal from social relations (Zimbardo 1990). Moral anxiety is linked with violation of ethical or moral principles; it may be manifested as a state of disintegration associated with a sense of guilt or shame. It may be reflected by doubts, disorganized system of values and decreased sense of achievement. Disintegrative anxiety occurs when the structure linking an individual with their environment is disrupted (Keppiński 2009). It appears if the existing order of things has been destroyed/upset; it contributes to disintegration of psychological functions; the individual loses his/her confidence in the existing situation and their activities become haphazard. Greater disintegration leads to more severe anxiety (Kępiński 2009).

There are also many other kinds of anxiety distinguished by psychologists. According to existential psychologists one of the types is existential anxiety, defined as a constant feeling of unease, always accompanying a person in their development, and "inherent" in their existence. It may take various forms, such as anxiety of death or of the unfamiliar (May 1950). There are three aspects of existential anxiety. Firstly, anxiety is related to destiny and death (Berman et al. 2006). The awareness of mortality produces a sense of a lack of control or of meaninglessness (Iverach et al. 2014). Ranschburg (1993, p.73) defines this state in the following way: "Death anxiety in a young person's mind is manifested as an anxiety related to the ultimate and unavoidable separation from 'the self' and puts the meaning of life in question". Another aspect of existential anxiety is a sense of vacuum and meaninglessness. This anxiety is expressed by the feeling that human life ultimately does not have any purpose. The third aspect associated with existential anxiety is linked with guilt and condemnation (Berman et al. 2006). Furthermore, one of the types of existential anxiety results from a fear of being alone. The diverse sources, forms and manifestations of anxiety are linked to one's culture and environment. According to Bauman, the greatest distress is linked with an anxiety which is blurry, diffuse, ambiguous, and non-specific. "Fear is the name we give to our uncertainty in the face of the dangers..., to our ignorance of what the threat is and our incapacity to determine what can and cannot be done to counter it" (Bauman 2006, p. 6).

Attempts to develop a typology of anxiety take into consideration the range of anxiety, type of stimuli/causes evoking anxiety as well as temporal characteristics of the emotion and its functions. Based on the above criteria, Cattell (1966) distinguished two types of anxiety, i.e. anxiety as a personality trait, and anxiety experienced in a specific situation. The factor structure of trait anxiety comprises poor inner integration, emotional immaturity, distrust and insecurity, tendency for self-blame, and mental tension. State anxiety is described as a number of feelings with a predominantly negative affect, occurring when an actual threat is being faced (Cattell 1966). Spielberger (1979) operationalized these two types of anxiety. Trait anxiety is defined as a quality of personality, resulting from numerous inner conflicts experienced in course of development, while state anxiety, also referred to as situational, is a response to crisis circumstances (Spielberger et al. 1995). State anxiety is defined as "subjectively and consciously perceived feeling of apprehension and tension, accompanied with activation and arousal" (Sosnowski et al. 2006, p. 5). Trait anxiety is a disposition or a tendency as a result of which an individual is likely to perceive harmless situations as threatening, and to respond to such situations disproportionately with state anxiety (Sosnowski et al. 2006). According to Spielberger, development of 'anxious personality' is linked with negative early childhood experiences. There is a certain relationship between state and trait anxiety, particularly if the Self is threatened. In such a case, individuals with high-level trait anxiety show a marked tendency to experience situational anxiety (Spielberger 1979). Generally, individuals with high- 
level trait anxiety are less likely to be satisfied with themselves, they use the strategy of self-blame and selfdeprecation (Öhman 2008). Spielberger's concept of anxiety is supplemented by the multidimensional model proposed by Endler. According to them, anxiety takes four forms: social, physical (biological), psychological (doubts, indecisiveness) and task-related (daily concerns). All these represent trait anxiety, but they can also be manifested as elevated state anxiety if specific stimuli activate the trait (Endler and Kocovski 2001). There are also other concepts, such as worry and panic, in the fear spectrum. They are described by linguistics as different from fear and anxiety in terms of intensity (Wierzbicka 1988). The most intense is panic, which is defined as a negative feeling related to current or future personal event and blocking of action. Worry, according to Wierzbicka (1988) and Shaver et al. (1987), is a negative feeling less intense than panic, longer-lasting, and related to higher indefiniteness.

It is noteworthy that emotions from the fear spectrum are also examined by scientists in the context of lay theories. There are many proponents of emotion lay theories. They define emotions as individual theories of the world. These theories are also scientific, however, they base on linguistic research. These proponents believe that understanding emotional concepts is impossible without thorough emotion lay theories analysis (Harré 1995; Oatley and Johnson-Laird 1995; Wierzbicka 1992b). The term 'lay' indicates the central location of a man in his 'first language', this language determines his image of the world and his attitudes towards the world and people (Apresjan 1994). All linguistic conceptions of emotions based on the natural language are lay conceptions. These theories study the lay-lexicon and show how ordinary people conceptualise the world (Wierzbicka 1992b). For instance, Russell argued that the terms such as alarmed, afraid, tense refer to negative valence and high intensity (Russell 1980). In the Morgan and Heise model, terms such as pertrified, terrified, and afraid have negative valence and low potency (Morgan and Heise 1988). According to Shaver and associates (Shaver et al. 1987), terms from the fear spectrum form different groups such as panic and anxiety. Then, the prototype of the fear spectrum concepts entails basic information on the causes of fear event, typical activity in a situation, typical symptoms of these emotions and consequences of such events. In general, lay conceptions of the fear spectrum emotions are focused on the lexical and semantic analyses of terms used by people.

\section{Emotional Verbal Fluency}

Verbal fluency techniques are among the well-known and widely recognized psychological tools used in assessing cognitive functions (Ardila and Ostrosky-Solís 2006). These techniques require a spontaneous word generation from predefined categories (Gawda and Szepietowska 2013, 2016). The standard applications of verbal fluency techniques relate to letter and category fluency tasks and quantitative analysis. This paper discusses a new qualitative-quantitative analysis of words and focuses on emotional verbal fluency tasks (EVT). These tasks involve listing of words associated with emotional categories. These involve emotional categories such as negative or positive, unpleasant, pleasant, love, fear, joy, sadness among many others (Gawda and Szepietowska 2013, 2016; Gawda et al. 2017; Sass et al. 2013). In literature, there are a few studies exploring emotional verbal fluency, however, they use traditional (quantitative) indicators, such as the number of correct responses, errors, clusters, and switches (e.g. Abeare et al. 2017; Gawda and Szepietowska 2013, 2016; Rossell 2006; Wauters and Marquardt 2017). The present analysis focuses on the content of semantic clusters identified on the basis on words produced by subjects. The semantic clusters content is noteworthy as it may reflect the emotional knowledge structure. We aim to identify the structure of emotional concepts within the fear spectrum. This approach is based on the evidence that verbal fluency performance is associated with the knowledge stored in episodic and semantic memory (Goñi et al. 2011) and that words generated in emotional verbal fluency tasks reflect this knowledge related to particular emotions. There are data indicating that words generated are related semantically to one another and that they form semantic clusters (Berto and Galaverna 2016). We assume that a semantic network composed of semantic clusters reflects the structure of the emotion concept. This approach has been inspired by other research into the semantic knowledge organization, such as an associative approach, a network approach based on verbal fluency data in the animal category assessment (Goñi et al. 2011), examination of verbal fluency in patients with cognitive impairment (Lerner et al. 2009), research in patients with frontal and right lobe damage (Schwartz and Baldo 2001), analysis of letter fluency taking into account concept organization (Schwartz et al. 2003), semantic memory organization among Alzheimer's disease patients (Chan et al. 1993), and patients with schizophrenia (Berto and Galaverna 2016; Robert et al. 1997). The examples of listed research are qualitative analyses of semantic or phonemic verbal fluency; they were not focused on emotional verbal fluency tasks.

The aim of the present study is to describe the structure of concepts within the fear spectrum, represented by the categories of worry, fear, anxiety, panic, and to show their differentiation based on verbal fluency material. In order to describe the structure of the concepts from the fear spectrum, EVFT tasks were used. To our knowledge, there is only one published research based on a similar methodology (Gawda 2019). This research showed that lay-people have extensive knowledge about emotional concepts and that their personal conceptualisations are associated with personality traits. In the examined context, anxiety is a particularly interesting trait as it was found to be differentiating for personal love concepts (Gawda 2019). Besides anxiety trait, described above, dogmatism is another personality 
trait potentially modifying the structure of personal emotional concepts. This assumption is based on the associations between anxiety and dogmatism development shown in research, e.g. there are indications that high-anxious subjects are biased for rigid and dogmatic attitudes and opinions (Furnham and Marks 2013). Dogmatism is defined as a personality trait associated with closed cognitive belief organization and disbeliefs about reality. It is an opposite trait to open-mindedness. Dogmatism is thought to be a cognitive structure, not just rigid thinking. This structure is related to authoritarianism, political persuasion, and religiosity. A dogmatic person displays oversimplified thinking and perception, and resistance to change attitudes or beliefs. Rokeach (1960) stated that this personality trait develops in infancy because of anxious relationships between children and parents. This kind of experience including fear is leading to form perseverativeness and can be the basis for formulation of dogmatic viewpoint. In effect, dogmatic thinking becomes a form of protection against negative affect (Schultz and Stone 1997).

\section{Hypotheses}

Given the presented data and theoretical background, the following hypotheses were formulated:

1. As these tasks rely on natural language, we assume that semantic clusters identified on the basis of the words from the fear spectrum tasks reflect personal concepts (layconcepts) of worry, fear, anxiety, and panic (Wierzbicka 1988, 1992a, b). We believe that these personal concepts have different structures (this is based on the linguistic research (Kurcz 1967; Shaver et al. 1987; Wierzbicka 1988). In this context, we expect that emotional verbal fluency technique has appropriate construct and discriminant validity.

2. We hypothesize that the components of the personal concept of fear are partly consistent with the scientific theories by Cattell, Spielberger, Öhman, and other approaches. We believe that the lay concepts of fear spectrum contain prototypical elements (such as causes, behaviors, places, results) and also other elements for fear situations, e.g. illness, existential and temporal aspects, because fear is related to a variety of factors (Barrett 2012, 2013, 2014).

\section{Study I}

\section{Method}

\section{Participants}

The study involved a randomly selected sample of 280 participants (150 women, 130 men) aged between 18 and 49 years old $(M=25.00, S D=3.9)$. They were all right-handed (control of handedness is important because it is related to functional brain asymmetry and linguistic skills, thus, it can impact linguistic task performance such as verbal fluency). They did not display neuropsychiatric, or somatic impairments, nor were addicted to drugs or alcohol (the screening questionnaire was used to collect the demographic and other data). Two subjects were excluded from the examination due to impairments. Every participant was a native Polish speaker; the study was conducted in Polish. The level of participants' education was similar. It was measured by the number of years of education (1213 years). They were college students, university students or workers. All participants completed EVF tasks, other verbal fluency tasks such as Animals, letter ' $\mathrm{k}$ '(phonemic fluency), WAIS-R, and self-report questionnaires.

\section{Procedure}

Initially, a preliminary examination was carried out using phonemic fluency (letter $k$ ) and Animals tasks, along with a vocabulary test measurement. Then, the participants were asked to list, in one minute, as many words as possible, for a given word-criterion. Four word-criteria were used: worry, fear, anxiety, panic (respectively in Polish: obawa, lęk, strach, panika). All the tasks were performed in Polish. The examination took place in a quite lab room. The four words-tasks were always performed in the same order because it requires a standard procedure of verbal fluency assessment. The change of order can affect the results. The words worry, fear, anxiety, and panic carry different distinctive meaning in Polish language, similarly as in English. According to linguists and culture researchers, there are more similarities between Polish and English emotional words than, for instance, between English and Japanese (Russell and Sato 1995; Wierzbicka 1992a). In English, these words are also associated with different emotional states, however, from the same spectrum. The differences between them vary; for instance, fear and anxiety are only subtly different, while fear and panic differ significantly (Kurcz 1967; Shaver et al. 1987). All the words generated by the participants were recorded by the experimenter and the assistant, and counted individually for each participant and for each task. The participants were asked to name words not phrases. If participants said statements instead of words, the experimenter corrected them and asked to name words. Every word listed for the specific tasks was treated as meeting the relevant criterion. This is due to the fact that emotional verbal fluency is particularly subjective; only mispronounced words or perseverations were found as incorrect responses. Then, other questionnaires were given to the participants (described below).

In the aforementioned study the protocol of experiments was approved by the Local Ethics Committee of Maria Curie-Sklodowska University. 


\section{The Words Materials}

1. Letter $\mathrm{k}$ (phonemic fluency): The subjects were asked to name as many as possible words starting with $\mathrm{k}$ letter within one minute. The number of correctly named words was taken into account in the statistical analyses related to construct validity of the EVFT.

2. Verbal fluency semantic task - Animals: The subjects were asked to name as many as possible animals in one minute. The number of correctly named animals was considered as a variable in the calculations related to the construct and discriminant validity of the EVFT.

3. The Emotional Verbal Fluency Technique (EVFT): The subjects were asked to name, in one minute, as many words as possible to match the four categories, separately; first worry, then fear, anxiety, and finally, panic. For all the categories, the following semantic clusters (a semantic cluster consists of at least two words generated in succession and related semantically, e.g. words men, women= cluster 'people') were identified by judges (The judges analysed the words material from tasks/categories, and they classified participant responses into categories, they listed semantic clusters, they named all semantic clusters basing on their content):

- Emotions/feelings (strictly emotional or emotionally loaded words, e.g. unease, fear, horror);

- Helplessness (terms representing a sense of helplessness, e.g. incapacity, feebleness, hopelessness);

- Diseases (names of illnesses or terms related to impairments, e.g. cancer, arachnophobia, insanity, schizophrenia, sickness);

- Somatic symptoms (various bodily manifestations or forms of expression, e.g. crying, sobbing, screaming, tears, injury);

- Causes and circumstances of non-extreme events (e.g. problem, public speaking, examinations, interviews);

- Extreme events (e.g. war, fire, death, terrorism, disasters, floods, tornado);

- Places (terms representing locations, e.g. school, workplace, home);

- Persons (terms related to individual people or groups, e.g. mother, professor, crowd, people);

- Activities/behaviors/actions (e.g. escape, worry, run, misunderstand);

- Animals (e.g. spider, moths, hornets, wasps);

- Existential and ethical aspects (terms pointing to general, universal aspects of life, e.g. evil, nihilism, dependence, awareness, God);

- Fictional situations/characters, (e.g. horror, ghosts, witches, monster, thriller);
- Duties/responsibilities, (e.g. work, learning, care, school, family, unemployment).

- Objects (e.g. axe, syringe, knife).

An example of the coding system applied for the emotional fluency task 'fear'.

Words produced by a subject $(\mathrm{Y})$ in response to the wordstimulus 'fear': uncertainty, trembling, sweat, worry, unease, unfamiliar, cancer, appraisal, life, death, people, powerlessness, work, defeat.

This is how the words generated were assessed. It was determined which semantic cluster the specific words belonged to. Subsequently the number of words in each semantic cluster was identified; finally the words were given in parentheses.

1. Number of words generated: 14

2. Emotions/feelings (terms describing emotions and feeling): 3 (uncertainty, worry, unease);

3. Helplessness (terms representing a sense of helplessness: 1 (powerlessness);

4. Diseases (names of illnesses or terms related to impairments: 1 (cancer);

5. Somatic symptoms (various bodily manifestations or types of expression: 2 (trembling, sweat);

6. Causes and circumstances of non-extreme events: 4 (unfamiliar, evaluation, work, defeat);

7. Extreme events: 2 (death, cancer);

8. Places (terms representing locations): 0 ;

9. Persons (terms related to individual people or groups: 1 (people);

10. Activities/behaviors/actions: 0;

11. Animals: 0;

12. Existential and ethical aspects (terms referring to general, universal aspects): 2 (life, death);

13. Fictional situations/characters: 0 ;

14. Duties/responsibilities: 1 (work).

15. Objects: 0

4. The Vocabulary subtest from the Wechsler Adult Intelligence Scale-Revised (WAIS-R). The WAIS is designed to measure general intelligence. It comprises 11 subtests grouped into two parts: performance and verbal. In order to estimate the verbal IQ, the WAIS-R Vocabulary subtest was used to assess verbal understanding, ability to classify concepts, abstract thinking, and to evaluate the subject's linguistic competence (Brzeziński et al. 2004). The scores of Vocabulary subtest were used in the screening procedure to qualify participants, i.e. to select only those subjects who had no impairments. Then, these scores were used in the correlational analyses. Vocabulary: Cronbach's alpha in the present study is .92 . 
5. The State-Trait Anxiety Inventory (STAI). The Trait and State Anxiety Scales were considered in the statistical analysis. The STAI comprises 20 statements describing emotional conditions. The respondents rate applicability of every statement to themselves on a 4-point scale: 1 rarely, 2 - sometimes, 3 - often, 4 - usually. The reliability and validity of the Polish adaptation of the STAI are very high (Sosnowski et al. 2006). In the present study: Trait anxiety - Cronbach's alpha is $=.88$. State anxiety - Cronbach's alpha is. 87.

\section{Statistical Analysis}

First, the descriptive statistics were computed and the semantic clusters were compared between the categories worry, fear, anxiety, and panic (Friedman tests were used, Wilcoxon tests were used for pairwise comparisons). All the statistics are presented in Table 1. In order to assess reliability, WKendall coefficients between judges' scores were calculated (Table 2) and Pearson's correlations were applied for testretest reliability assessment (Study II). Construct validity was established with Pearson's correlations between the EVFT scores and Animals, and letter ' $\mathrm{k}$ ' scores (Table 3). Likewise, Pearson's correlations were computed to assess discriminant validity between the EVFT' scores and the STAI and the Vocabulary from the WAIS-R (Tables 3 and 4). To examine the internal relationships in the structure of the example emotional concept, hierarchical clustering analysis was performed for the anxiety category. It was done only for 'anxiety' category, not for all four categories.

\section{Results}

\section{Reliability}

First, reliability of the EVFT was examined with inter-judge correlations (W-Kendall tests). Table 2 shows that the correlations between the judges' assessments for different semantic clusters are very high (they range from .82 to .99 ). This shows that the criteria/indicators of EVFT, such as the number of words, errors, types of semantic clusters, were clear for the independent judges.

\section{Validity}

Construct validity Construct validity of EVFT was tested by Pearson's correlations between EVFT (semantic clusters and number of words in the categories worry, fear, anxiety, panic) and the other fluency tests (Animals, letter ' $\mathrm{k}$ '). Table 3 presents significant correlations (ranging from .36 to .45), which indicates that the numbers of words produced in EVFT and in animals and letter ' $k$ ' tasks were correlated. This provides evidence for convergent validity of EVFT. This means that EVFT measures partly the same cognitive functions as the other verbal fluency tests.
Table 1 Study I - Descriptive statistics and comparisons between categories

\begin{tabular}{|c|c|c|c|c|c|}
\hline Variables & $\begin{array}{l}\text { Worry } \\
(n=280) \\
M(S D)\end{array}$ & $\begin{array}{l}\text { Fear } \\
(n=280) \\
M(S D)\end{array}$ & $\begin{array}{l}\text { Anxiety } \\
(n=280) \\
M(S D)\end{array}$ & $\begin{array}{l}\text { Panic } \\
(n=280) \\
M(S D)\end{array}$ & $x^{2}(3)$ \\
\hline Number of words & $5.77(3.88)^{\mathrm{a}}$ & $5.93(2.14)^{\mathrm{a}}$ & $5.32(2.56)^{\mathrm{b}}$ & $6.05(2.96)^{\mathrm{c}}$ & $34.64 * * *$ \\
\hline Number of errors & $.01(.03)^{\mathrm{a}}$ & $.03(.4)^{\mathrm{a}}$ & $.02(.05)^{\mathrm{a}}$ & $.03(.03)^{\mathrm{a}}$ & $2.35 \mathrm{~ns}$ \\
\hline SC: Emotions & $2.49(1.58)^{\mathrm{a}}$ & $2.13(.89)^{\mathrm{b}}$ & $1.80(1.39)^{\mathrm{c}}$ & $1.37(1.06)^{\mathrm{d}}$ & $38.12 * * *$ \\
\hline SC: Helplessness & $.15(.42)^{\mathrm{a}}$ & $.15(.45)^{\mathrm{a}}$ & $.17(.53)^{\mathrm{a}}$ & $.36(.66)^{\mathrm{b}}$ & $25.66 * * *$ \\
\hline SC: Diseases & $.04(.20)^{\mathrm{a}}$ & $.56(.75)^{\mathrm{b}}$ & $.54(.98)^{\mathrm{b}}$ & $.17(.55)^{\mathrm{c}}$ & $107.45^{* * *}$ \\
\hline SC: Symptoms & $.39(.92)^{\mathrm{a}}$ & $.58(.35)^{\mathrm{b}}$ & $.53(1.00)^{\mathrm{b}}$ & $.94(1.33)^{\mathrm{c}}$ & $66.21 * * *$ \\
\hline SC: Non-extreme & $1.42(1.60)^{\mathrm{a}}$ & $1.15(1.10)^{\mathrm{b}}$ & $.95(1.17)^{\mathrm{b}}$ & $.69(.98)^{\mathrm{c}}$ & $36.23 * * *$ \\
\hline SC: Extreme & $.17(.61)^{\mathrm{a}}$ & $.14(.43)^{\mathrm{a}}$ & $.19(.55)^{\mathrm{b}}$ & $.86(1.30)^{\mathrm{c}}$ & $163.23 * * *$ \\
\hline SC: Places & $.08(.31)^{\mathrm{a}}$ & $.07(.30)^{\mathrm{a}}$ & $.10(.34)^{\mathrm{a}}$ & $.07(.36)^{\mathrm{a}}$ & $2.56 \mathrm{~ns}$ \\
\hline SC: People & $.19(.59)^{\mathrm{a}}$ & $.18(.45)^{\mathrm{a}}$ & $.12(.36)^{\mathrm{b}}$ & $.32(.59)^{\mathrm{c}}$ & $36.74 * * *$ \\
\hline SC: Activity & $.13(.40)^{\mathrm{a}}$ & $.15(.46)^{\mathrm{a}}$ & $.18(.50)^{\mathrm{a}}$ & $.85(.97)^{\mathrm{b}}$ & $141.23 * * *$ \\
\hline SC: Animals & $.05(.33)^{\mathrm{a}}$ & $.08(.34)^{\mathrm{a}}$ & $.07(.32)^{\mathrm{a}}$ & $.09(.33)^{\mathrm{a}}$ & $5.31 \mathrm{~ns}$ \\
\hline SC: Existential & $.14(.63)^{\mathrm{a}}$ & $.29(.57)^{\mathrm{b}}$ & $.28(.54)^{\mathrm{b}}$ & $.18(.50)^{\mathrm{c}}$ & $27.32 * * *$ \\
\hline SC: Fiction & $.09(.56)^{\mathrm{a}}$ & $.14(.46)^{\mathrm{b}}$ & $.15(.49)^{\mathrm{b}}$ & $.04(.24)^{\mathrm{a}}$ & $23.16^{* * *}$ \\
\hline SC: Duties & $.22(.56)^{\mathrm{a}}$ & $.02(.30)^{\mathrm{b}}$ & $.02(.33)^{\mathrm{b}}$ & $.01(.14)^{\mathrm{b}}$ & $38.12 * * *$ \\
\hline SC: Objects & $.12(.77)^{\mathrm{a}}$ & $.06(.32)^{\mathrm{b}}$ & $.07(.33)^{\mathrm{b}}$ & $.05(.26)^{\mathrm{b}}$ & $.65 \mathrm{~ns}$ \\
\hline
\end{tabular}

$S C$ semantic cluster, $M$ mean, $S D$ standard deviation, $* * * p<.001$

abcd The same superscript for means in a row indicate no significant difference by Wilcoxon test $p<.01$ 
Discriminant validity Two techniques were used to establish discriminant validity, i.e. the State-Trait Anxiety Inventory and the WAIS-R Vocabulary subtest. Pearson's correlations were calculated between the EVFT and STAI scores, and the Vocabulary subscale. Table 3 shows there are significant correlations between the number of words produced during the EVFT in the categories of worry, fear, anxiety and panic and in the Vocabulary subtest. Conversely, there is no significant correlation between the scores in the STAI and EVFT total number of correct responses in the categories within the fear spectrum. However, there are many significant correlations between the number of words in the semantic clusters identified in the EVFT category within fear spectrum, namely Emotions, Symptoms, and Activities and the STAI scores. These results show that the number of words produced in the EVFT categories within fear spectrum partly measure verbal intelligence and that particular semantic clusters identified in the EVFT are associated with the scores of the State-Trait Inventory (see Table 4). This means that the content of the particular EVFT semantic cluster is a measure of similar aspects as those assessed by the STAI but not by the total number of responses in the categories within the fear spectrum. The existence of positive significant correlations between the content of the fear spectrum clusters (EVFT) and the STAI confirm discriminant validity of the EVFT.

\section{Comparisons between categories worry, fear, anxiety, and panic}

The number of words in semantic clusters has been compared between the four tasks of worry, fear, anxiety, and panic. Results of these comparisons are presented in Table 1. In worry category there are a lot of words related to emotions, feelings, causes and circumstances of non-extreme events (effect size: $\mathrm{V}=.30, p<.001)$; the highest number of words refers to objects and duties $(\mathrm{V}=.35, p<.001)$. The structure of semantic clusters in the categories of fear and anxiety is different from that observed in the category of worry. Fear and anxiety are more similar than the other categories. In the structure of fear there are a lot of words related to symptoms, illnesses, emotions and existential aspects. In anxiety various causes of non-extreme events are included, e.g. diseases and somatic symptoms $(\mathrm{V}=.55, p<.001)$. There are also existential aspects $(\mathrm{V}=.59, p<.001)$ and references to fiction $(\mathrm{V}=.29, p<.001)$. The structure of the category of panic is also different compared to worry, fear, and anxiety. Apart from the words related to emotions in panic category, a lot of specific elements dominate, such as strong focus on helplessness, somatic symptoms $(\mathrm{V}=.29, p<.001)$, extreme causes and circumstances $(\mathrm{V}=.46, p<.001)$, activity and human behaviors $(\mathrm{V}=.22, p<.05)$ and rare references to fiction or duties. Besides, compared to the other categories, panic is more commonly associated with people $(\mathrm{V}=.28, p<.01)$. In all these comparisons, contingency coefficients indicate significant effect. Only such semantic clusters as objects, animals and places do not differentiate the categories of worry, fear, anxiety, and panic (see Figs. 1, 2, 3).

\section{Hierarchical Clustering Analyses of the Category 'Anxiety'}

Due to the infrequent use of some words, the variables were grouped to enable hierarchical clustering analyses. Hence, the variables of Place, Animals, Objects, Diseases and Duties were included into the cluster Non-extreme causes; the subsequent analysis was carried out in this form. The presented data (Fig. 4) show that in the category of anxiety, the semantic clusters create two major threads. The first one comprises symptoms, behaviors and emotions, the other one includes existential aspects, extreme causes, helplessness, persons, non-extreme causes, and fiction. Therefore, the category of anxiety comprises information related to causes of this condition; of key importance among these are people encumbered in non-extreme and extreme events and circumstances. The structure also includes symptoms of anxiety, emotions and behaviors typical for a state of anxiety, as well as additional elements such as Fictional aspects. The structure of the category of anxiety provides information on emotions usually experienced in such states; these include fear, unease, concern and sense of helplessness. Importantly, the structure of this category/concept contains a lot of information on somatic and other symptoms, including diseases, i.e. experiences potentially associated with anxiety, and consequences of this

Table 2 Study I - The inter-judge correlations (W-Kendall tests)

\begin{tabular}{lllll}
\hline Variables & $\begin{array}{l}\text { Worry } \\
(n=280)\end{array}$ & $\begin{array}{l}\text { Fear } \\
(n=280)\end{array}$ & $\begin{array}{l}\text { Anxiety } \\
(n=280)\end{array}$ & $\begin{array}{l}\text { Panic } \\
(n=280)\end{array}$ \\
\hline Number of words & $.99 * * *$ & $.99 * * *$ & $.99 * * *$ & $.99 * * *$ \\
Number of errors & $.99 * * *$ & $.99 * * *$ & $.99 * * *$ & $.99 * * *$ \\
SC: Emotions & $.98 * * *$ & $.97 * * *$ & $.98 * * *$ & $.97 * * *$ \\
SC: Helplessness & $.97 * * *$ & $.96 * * *$ & $.96 * * *$ & $.96 * * *$ \\
SC: Diseases & $.96 * * *$ & $.95 * * *$ & $.96 * * *$ & $.96 * * *$ \\
SC: Symptoms & $.93 * * *$ & $.94 * * *$ & $.96 * * *$ & $.96 * * *$ \\
SC: Non-extreme & $.94 * * *$ & $.93 * * *$ & $.94 * * *$ & $.94 * * *$ \\
SC: Extreme & $.87 * * *$ & $.91 * * *$ & $.84 * * *$ & $.84 * * *$ \\
SC: Places & $.93 * * *$ & $.94 * * *$ & $.93 * * *$ & $.93 * * *$ \\
SC: People & $.94 * * *$ & $.98 * * *$ & $.93 * * *$ & $.95 * * *$ \\
SC: Activity & $.93 * * *$ & $.92 * * *$ & $.93 * * *$ & $.94 * * *$ \\
SC: Animals & $.97 * * *$ & $.98 * * *$ & $.98 * * *$ & $.98 * * *$ \\
SC: Existential & $.92 * * *$ & $.91 * * *$ & $.90 * * *$ & $.91 * * *$ \\
SC: Fiction & $.94 * * *$ & $.95 * * *$ & $.94 * * *$ & $.95 * * *$ \\
SC: Duties & $.86 * * *$ & $.84 * * *$ & $.83 * * *$ & $.82 * * *$ \\
SC: Objects & $.91 * * *$ & $.89 * * *$ & $.90 * * *$ & $.95 * * *$ \\
\hline
\end{tabular}

$* * * p<.001$, Abbreviation: $S C$ semantic cluster 
Table 3 Study I - Correlations between the EVFT (number of words), other verbal fluency tasks (number of correct responses), and other measures

\begin{tabular}{lcccc}
\hline Variable & EVFT worry & EVFT fear & EVFT anxiety & EVFT panic \\
\hline VF: Letter k $(n=280)$ & $.40^{* * *}$ & $.43 * * *$ & $.43 * * *$ & $.40^{* * * *}$ \\
VF: Animals $(n=280)$ & $.41^{* * *}$ & $.44 * * *$ & $.46^{* * * *}$ & $.42^{* * * *}$ \\
VOC $(n=280)$ & $.43^{* * *}$ & $.44 * * *$ & $.44 * * *$ & $.42^{* * * *}$ \\
STAI-state $(n=280)$ & $.06 \mathrm{~ns}$ & $.09 \mathrm{~ns}$ & $.09 \mathrm{~ns}$ & $.02 \mathrm{~ns}$ \\
STAI-trait $(n=280)$ & $.02 \mathrm{~ns}$ & $.03 \mathrm{~ns}$ & $.02 \mathrm{~ns}$ & $.03 \mathrm{~ns}$ \\
\hline
\end{tabular}

***- $p<.001, n s$ non-significant; Abbreviations: EVFT Emotional Verbal Fluency Technique, $V F$ verbal fluency technique, VOC Vocabulary, subscale from WAIS-R, STAI results from the State-Trait Anxiety Inventory condition (Fig. 4). This is generally consistent with data related to the structure of concepts (Niedenthal 2008).

\section{Study II}

This study was conducted two months after study I to verify test-retest reliability. The second study was designed to verify the semantic structure of the concepts within the fear spectrum and to demonstrate its relationship with personality traits such as trait anxiety and dogmatism.

\section{Hypotheses}

1. We believe that people present a relatively constant tendency in emotional word association (semantic clusters) in verbal fluency tasks. This is based on data confirming the constancy in word association (Bartczak et al. 2010). Furthermore, we assume that emotional verbal fluency technique is a reliable measure.

2. We believe that the structure of lay concepts within the fear spectrum is associated with mental rigidity and trait

Table 4 Study I - Correlation between the EVFT (semantic clusters i.e. number of words in a cluster) and the STAI $(n=280)$

\begin{tabular}{lclc}
\hline EVFT & Semantic cluster & Trait anxiety & State anxiety \\
\hline Worry & Emotions & $.13^{*}$ & $.13^{*}$ \\
& Symptoms & $.21^{* *}$ & $.22^{* *}$ \\
& Activities & $.07 \mathrm{~ns}$ & $.08 \mathrm{~ns}$ \\
Fear & Emotions & $.83^{* *}$ & $.10 \mathrm{~ns}$ \\
Anxiety & Symptoms & $.22^{* *}$ & $.21^{* *}$ \\
& Activities & $-.19^{* *}$ & $-.20^{* *}$ \\
& Emotions & $.19^{* *}$ & $.11 \mathrm{~ns}$ \\
& Symptoms & $.16^{*}$ & $.21^{* *}$ \\
& Activities & $-.13^{*}$ & $-.01 \mathrm{~ns}$ \\
Panic & Emotions & $-.09 \mathrm{~ns}$ & $.02 \mathrm{~ns}$ \\
& Symptoms & $-.08 \mathrm{~ns}$ & $.00 \mathrm{~ns}$ \\
& Activities & $.09 \mathrm{~ns}$ & $-.14^{*}$ \\
\hline
\end{tabular}

Abbreviations: EVFT Emotional Verbal Fluency Technique, STAI StateTrait Anxiety Inventory

$*_{-} p<.05, * *_{-} p<.01, n s$ non-significant anxiety. Particularly, trait anxiety affects concept structure by contributing negative elements, whereas mental rigidity predicts poor differentiation of the concept structure, i.e. people with high dogmatism name similar words in tasks related to different emotions: worry, fear, anxiety, panic. Our hypotheses are based on the relationship data between anxiety and dogmatism (Furnham and Marks 2013). Thus, we assume that highly dogmatic individuals can generate less varied words during fear spectrum tasks performance.

\section{Method}

\section{Participants}

A sample of 190 participants (100 women, 90 men), between 18 and 50 years of age, were examined $(\mathrm{M}$ age $=25.00, \mathrm{SD}=$ 4.57). The participants of study I participated in Study II. All of them were right-handed and did not display psychiatric, neurological, or somatic impairments. They were not addicted

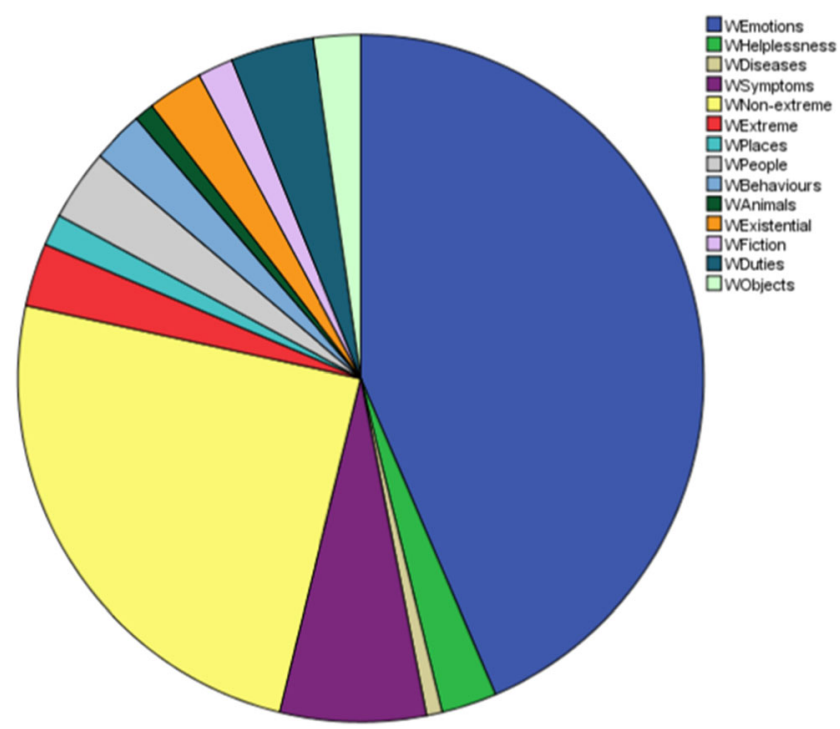

Fig. 1 Study I. Structure of the concept 'worry' 


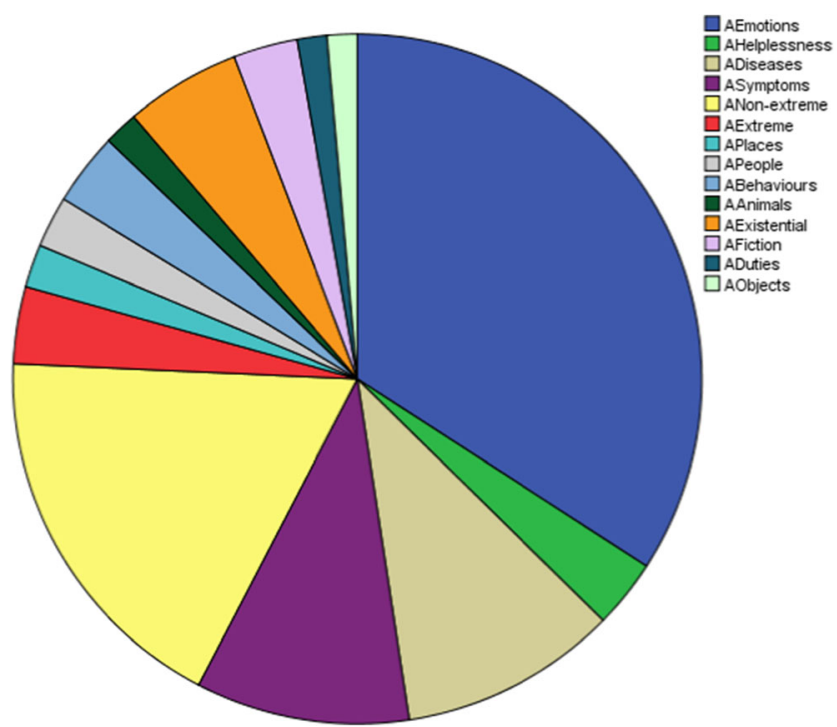

Fig. 2 Study I. Structure of the concept 'anxiety'. The structure of the concept 'fear' is very similar to the structure of 'anxiety 'category with details presented in Table 1

to drugs or alcohol (demographic and other data based on the screening questionnaire). The level of education of participants was similar: about 12-13 years. All participants were native Polish speakers. The research was conducted in a laboratory. The participants individually completed the EVFT, other verbal fluency tasks, i.e. Animals, letter ' $k$ ', and the Rokeach Dogmatism Scale.

\section{Procedure and Measures}

1. Tasks 'letter k' (phonemic fluency) and Animals were conducted following the same procedure as in Study I.

2. The EVFT: the same procedure was applied as in Study I; the participants named all words coming to their mind

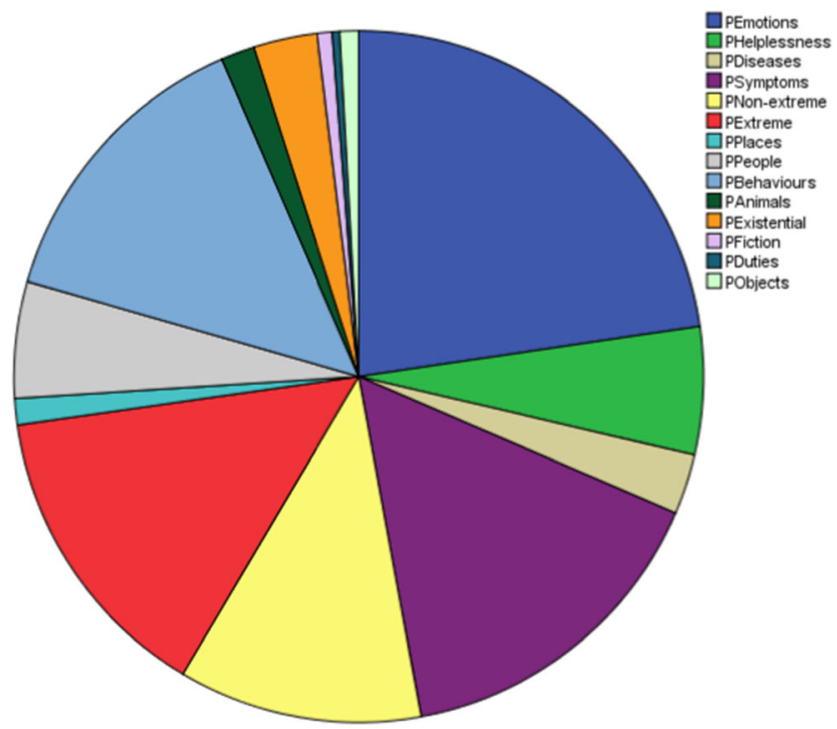

Fig. 3 Study I. Structure of the concept 'panic' representing the categories of fear, anxiety, worry, and panic. The same semantic clusters were identified from the generated words by participants as in Study I. The additional indicator named Categories diversity was applied in Study 2 to verify the relationship between dogmatism and complexity of the emotional concept within fear spectrum.

Categories diversity (assessment by three competent judges): from 1 (no diversity, the subjects produce the same words in all the tasks, repeat the same words for worry, anxiety, panic), to 7 (the words are largely varied; no repetitions; qualitative differences between the categories/clues). Example showing a lack of differences between the categories/ low diversity of the terms between the categories/clues (rating 1 point): Worry: fear, meeting, scared, escape, confusion. Anxiety: scared, fear, confusion, escape, meeting. Panic: fear, escape, scared, confusion, restlessness. Example of large differences between the categories (rating 7 points): Worry: fear, sadness, unease, divorce, humans, life. Anxiety: examination, trembling, hands, result, dreams, nightmares, escape. Panic: people, screams, racing, shaking, dodging, fall, corpses, death. The understanding and measurement of category diversity/complexity makes reference to the concept of emotional differentiation or emotional granularity, which assumes that individuals presenting high level of divergence/differentiation/granularity produce more varied adjectives describing emotional experiences, while subjects presenting low degree of granularity produce similar/the same emotion adjectives (Kashdan et al. 2015, p. 11). The inter-rater agreement between judges in the categories diversity assessment was high (correlations ranged between .94 and .98). Category diversity was provided as categorical variables because there is no similar measure to assess diversity in verbal fluency material. This is not the same as number of words generated by a person. It refers to words' quality and their meaning. This is a particular property of the whole word category produced by a participant. Category differentiation was introduced with the purpose to evaluate its relationship with dogmatism.

\section{The Dogmatism Scale}

Like in Study I, the STAI was used. Applied additionally, the Dogmatism Scale by Rokeach (1960) contains 21 items (translation into Polish by Kossowska 2005). This Scale was used in the assessment of discriminant validity It measures dogmatism, defined as "unjustified certainty" on a 6point Likert-Type scale (with possible responses from Strongly disagree to Strongly agree). The scale's psychometric properties such as reliability and validity are adequate, for instance, Cronbach alfa $=.78$. In the present study a Cronbach's alpha is .73. 


\section{Results}

The analysis of the relationship between the words produced by participants allows to identify the same semantic clusters as in Study I. This confirms similarities in word associations. Then, test-retest reliability of the EVFT was assessed using Pearson's correlations. The test-retest measures are also significant and high (ranging between .79 and .99, see Table 5). These results show that the criteria of EVFT such as types of semantic clusters were correctly defined and they were clear for the independent judges. In Study II, we focused on the differentiation of the concept structure in relation to trait anxiety and dogmatism. A comparison of the semantic clusters content within the anxiety concept structure in individuals with low and high levels of trait anxiety suggests that there are many significant differences. In individuals with highlevel of trait anxiety, the concept structure predominantly points to ordinary, non-extreme causes of anxiety-evoking situations $\left(\mathrm{F}_{(1,188)}=4.61, p<., 01, \eta^{2}=, 06\right)$ and persons associated with such situation $\left(\mathrm{F}_{(1,188)}=3.40, p<.05, \eta^{2}=.05\right)$. In the subjects with low-level trait anxiety, the dominating information relates to fictional factors linked to anxiety $\left(\mathrm{F}_{(1,188)}=\right.$ $\left.3.39, p<.05 \eta^{2}=.05\right)$ as well as places $\left(\mathrm{F}_{(1,188)}=2.96, p<.05\right.$ $\eta^{2}=.04$ ). There is also a difference in existential elements comprised in the concept structure; these are more frequently pointed out in individuals with low-level trait anxiety. There were no significant differences between high-anxious and low-anxious persons in the following semantic clusters of anxiety category: emotions, helplessness, diseases, symptoms, extreme causes, activity, animals, duties, and objects.
Cognitive rigidity was operationalized using results in the Rokeach Dogmatism Scale. It was established that higher cognitive rigidity contributes to lower diversity of the emotional concepts in the spectrum of fear $\left(\mathrm{F}_{(1,188)}=.15 .67, p<.001\right.$, $\left.\eta^{2}=.07\right)$. Cognitively rigid individuals show concept representations which are poorly differentiated (Fig. 5). Highly dogmatic individuals present poorly varied structure in the concepts of worry, fear, anxiety, and panic. The subjects with a high level of dogmatism were found to produce very similar words in response to the four word-stimuli, while the subjects with low level of dogmatism produced different words in the specific tasks (Fig. 5).

\section{Discussion}

\section{Hypothesis 1 (Regarding Study I) Assuming that Emotional Verbal Fluency Technique Reveals people's Concepts within the Fear Spectrum and that these Lay Concepts Have Different Structures}

The results confirm that lay-people not only differentiate the concepts within the spectrum of fear, such as worry, fear, anxiety and panic, in terms of their intensity; they also present varied structures of each of these concepts. Generally, the structure of these emotional categories implies a certain knowledge related to the given emotion and, suggests that these emotional concepts comprise information on the causes and circumstances, people involved with such circumstances,
Fig. 4 Study I - relationship between semantic clusters of the category 'anxiety'

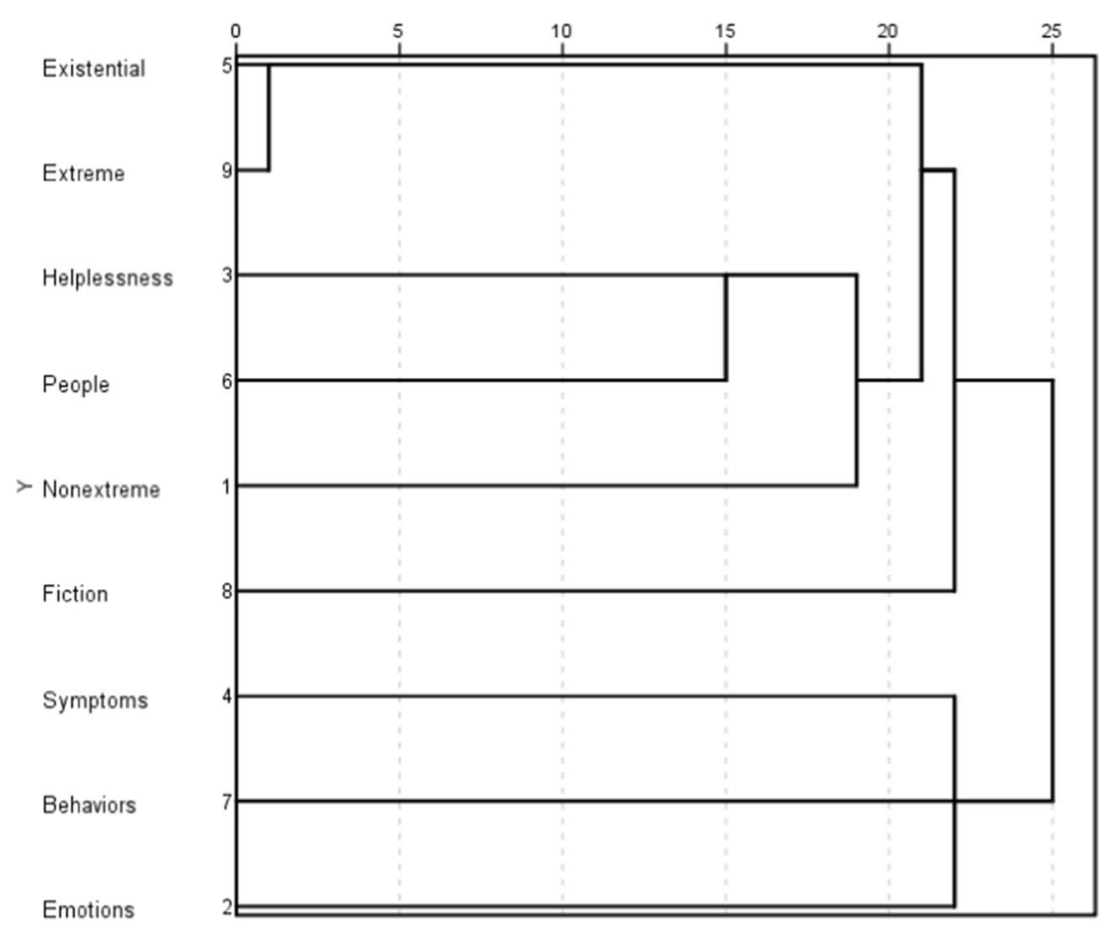


Table 5 Test-retest correlations. Similarity between the semantic clusters of the category Worry in Study I and Study II (Semantic clusters i.e. number of words in a cluster)

Correlations between the number of words in the clusters in Study 1 and Study 2

\begin{tabular}{llllllllllllll}
\hline II & II & II & II & II & II & II & II & II & II & II & II & II & II \\
Emot & Help & Dise & Sympt & Non-e & Extre & Places & People & Activ & Anim & Exist & Fiction & Duties & Objects \\
\hline $.998 *$ & .028 & -.033 & .098 & -.165 & -.101 & -.110 & .093 & .081 & -.051 & -.253 & -.142 & -.276 & -.253 \\
.028 & .984 & .045 & .249 & -.053 & -.023 & -.022 & -.119 & -.131 & .090 & .070 & -.019 & .029 & .063 \\
-.033 & .045 & .978 & .024 & -.155 & .113 & .110 & .020 & -.072 & .123 & .034 & -.036 & .010 & .277 \\
.098 & .249 & .024 & .956 & .095 & .032 & .068 & .251 & -.089 & .171 & .280 & .375 & -.086 & .167 \\
-.165 & -.053 & -.155 & .095 & .923 & .360 & -.009 & .401 & -.224 & .096 & .346 & .377 & .211 & .008 \\
-.101 & -.023 & .113 & .032 & .360 & .898 & .035 & .204 & -.052 & .059 & .017 & .014 & .135 & .313 \\
-.110 & -.022 & .110 & .068 & -.009 & .035 & .796 & .141 & -.093 & .057 & .256 & .253 & .013 & .348 \\
.093 & -.119 & .020 & .251 & .401 & .204 & .141 & .793 & -.023 & .002 & .407 & .424 & .094 & .319 \\
.081 & -.131 & -.072 & -.089 & -.224 & -.052 & -.093 & -.023 & $\mathbf{9 1 2}$ & -.054 & -.081 & -.058 & -.135 & -.057 \\
-.051 & .090 & .123 & .171 & .096 & .059 & .057 & .002 & -.054 & .901 & .161 & .307 & -.062 & .258 \\
-.253 & .070 & .034 & .280 & .346 & .017 & .256 & .407 & -.081 & .161 & .845 & .759 & .085 & .329 \\
-.142 & -.019 & -.036 & .375 & .377 & .014 & .253 & .424 & -.058 & .307 & .759 & .793 & -.033 & .215 \\
-.276 & .029 & .010 & -.086 & .211 & .135 & .013 & .094 & -.135 & -.062 & .085 & -.033 & .794 & .032 \\
-.253 & -.063 & .277 & .167 & .008 & .313 & .348 & .319 & -.057 & .258 & .329 & .215 & .032 & $\mathbf{. 9 9 4}$ \\
\hline
\end{tabular}

Emot Emotion, Dise Diseases, Non-e Non-extre

*Bold correlations are significant $p<.001$

symptoms, behaviors and consequences of the situation. These findings are in line with other evidence (Frijda 2008). The structure of the concept of worry includes a set of information related to the causes of this condition, of key importance among these are people involved in non-extreme events and circumstances. Of fundamental significance here are responsibilities/duties; they are the most frequent cause of worry and are inherent in the concept of worry. The structure of the concept of worry also provides information on the emotions usually experienced in such situations, e.g. fear, unease, concern, sense of helplessness. Importantly, the structure of this concept contains a lot of information on somatic and other symptoms, including diseases, i.e. experiences potentially associated with worry, as well as numerous behaviors and consequences of this condition. Analysis of the semantic clusters related to the categories of fear and anxiety suggests that the structure of both fear and anxiety contains prototypical elements, such as information on non-extreme social causes, physical threat (fear of injury) and new unfamiliar situations, as well as a lot of information on manifestations of such conditions (physiological, bodily symptoms such as trembling, shaking, crying), behaviors and cognitive responses (restless walking, loss of control) and consequences of such a situation. This is consistent with the concept of fear based on a prototype approach (Shaver et al. 1987; Shaver et al. 1992). In addition to the prototypical information, the subjects provided a lot of input falling outside the prototype such as existential aspects, objects, persons, animals, and fiction.

An interesting finding relates to differences in the structure of fear and anxiety concepts. Fear contains more references to animals and objects, and anxiety to diseases and emotions. The more frequent references to animals and objects suggest that fear is more closely linked to specific physical threats which may directly affect an individual. On the other hand, the fact that the structure of anxiety contains more references

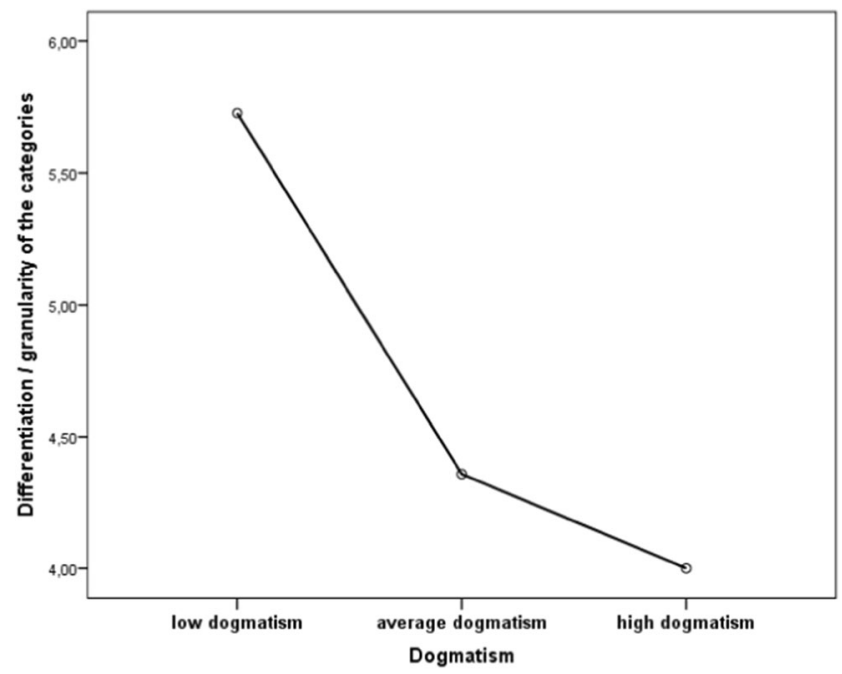

Fig. 5 Study II. Relationship between diversity/differentiation of the categories (fear, anxiety, worry, panic) and dogmatism $(n=190)$ 
to Diseases and Emotions suggests that anxiety is oriented towards the future and reflects premonitions related to potential threat posed by a disease. Furthermore, disease appears here as a potential category, and as an effect of anxiety. The subjects point out that anxiety may lead to a mental disorder or is a manifestation of a mental disease.

In sum, emotional verbal fluency technique is shown as a valid measure in terms of construct and discriminant validity. This is consistent with the previous findings related to the research focused on the love concept (Gawda 2019).

\section{Hypothesis 2 (Regarding Study I) Concerning Components of the Lay Concept of the Fear Spectrum Partly Consistent with the Scientific Theories by Cattell, Spielberger, Öhman, and Other Approaches}

Generally, this analysis of the material acquired using the verbal fluency technique confirms the legitimacy of the types of anxiety distinguished in the literature. Despite the similar physiological and behavioral manifestations, the disparities in the structure of the concepts suggest there are differences in subjective experiences of various types of anxiety. It was also established that the typical distinction between fear and anxiety, applied in the related literature, is indeed reflected in the structure of the concepts (Spielberger et al. 1995). According to both common and scientific conceptualization, the notion of fear is linked to direct physical danger, and anxiety to less specific threat (Endler and Kocovski 2001; LeDoux 2015). The structure of anxiety contains more emotions, such as unease, worry, uncertainty, apprehension, etc., which suggests that anxiety is more "emotional" than fear, or is associated by people with something that is affective, intangible, unspecified, and involves feeling rather than action/activity. This is also consistent with scientific conceptions (Barlow 2002; Bauman 2006; Öhman et al. 2000). The category of panic, in turn, most commonly contains information linked with extreme causes, manifestations, emotions and increased activity. This shows that panic has the highest dynamics among the relevant concepts in the spectrum of fear. It essentially involves a very strong response to an extreme event, leading to intensified action, most commonly expressed as escape. The structure of this emotion reflects its nature. However, compared to the concept of fear discussed in accordance with the prototype approach by Shaver et al. (1987), the results of the EVF tasks show that the structure of the concepts contains different elements falling outside the prototype construct (Barrett 2012, 2014; Barrett et al. 2007). The elements contributing to the complexity of the concept include for instance existential aspects and fictional situations, as well as words related to people involved in a situation of fear or anxiety, and specific types of factors such as animals and objects linked with the situation. This means that, in addition to prototypical information, the structure of the concepts comprises a variety of contents constituting a kind of peripheral layer/ surrounding the core of the concept (Gawda 2019). Natural concepts in the spectrum of fear have a structure which is partly consistent with conceptions proposed by researchers (Izard 1992; Shaver et al. 1987; LeDoux 2015; Öhman et al. 2000), yet the structure seems to be more varied, which shows that lay people have a broad knowledge of emotions in the spectrum of fear.

The present research confirmed the findings showed in many studies show that the emotional concepts include a number of elements such as interoceptive data (Barrett et al. 2007; Wilson-Mendenhall et al. 2013), specific exteroceptive data such as auditory, visual, and olfactory information (WilsonMendenhall et al. 2011, as well as data on activities associated with a given emotion (Oosterwijk et al. 2014). Emotional concepts also contain abstract elements, information about the person's relationship with his/her environment, surroundings, other people, information obtained from a wide range of cultural resources faced by the person, as well as specific data acquired during individual experiences, e.g. specific bodily sensations, perceptual data related to some emotional situations experienced by the person (Lindquist 2013). The structure of emotional concepts identified by examining the material collected using emotional verbal fluency tasks corresponds to the findings referred to above.

\section{Hypothesis 1 (Regarding Study II) Concerning Constant Tendency in Emotional Word Association (Semantic Clusters) in Verbal Fluency Tasks and method's Reliability}

The current data suggest that emotional verbal fluency is a reliable (across raters and time) and accurate method to describe the structure of emotional concepts within the fear spectrum. The results confirm the relatively constant tendency to produce emotional word associations. The tendency of generating similar word association has been shown in previous research in reference to other than emotional words (e.g. Bartczak et al. 2010; Russell and Jenkins 1954; Russell and Messeck 1959). The present research confirmed the stable tendency to generate specific semantic cluster (word associations) within verbal fluency tasks of the fear spectrum.

\section{Hypothesis 2 Regarding Study II: The Structure of Lay Concepts within the fear Spectrum Is Modified by Dogmatism (Mental Rigidity) and Trait Anxiety}

In addition to the characteristics of the differences in the structure of the concepts in the spectrum of fear, it was shown that there are disparities in the structure of the concepts depending on such individual traits as the level of dogmatism, verbal intelligence, and trait anxiety. Generally, verbal intelligence modifies the structure of concepts in the spectrum of fear, 
which is reflected by the fact that a higher level of intelligence corresponds to greater amount of information regarding emotions linked to potential states of anxiety, and to characteristics of people involved in related situations; it also enables more clear-cut perception of such situations. On the other hand, dogmatism/cognitive rigidity contributes to small diversity of emotional concepts in the spectrum of fear. Cognitively rigid individuals have poorly varied concept representations in terms of the intensity of the emotions in the fear spectrum. This most possibly may lead to undifferentiated responses in varied circumstances (Furnham and Marks 2013). The contents of the concepts are shaped by life experiences gained in the process of identification, classification and coding of meanings. Hence, the contents of the concepts reflect experiences of cognitively rigid persons. The present study quite clearly illustrates the claim that individuals characterized by cognitive rigidity are found with less elaborate categories of concepts related to the fear spectrum. The structure of these concepts contains less information about the causes and circumstances inducing fear/anxiety, less information about people associated with such situations, less information on the emotions and feelings potentially occurring in such situations, or diseases as the specific causes or consequences of such states. Such composition of concepts in the fear spectrum adversely affects the ability of cognitively rigid individuals to understand the diversity of situations in their lives (Schultz and Stone 1997).

Furthermore, it was shown that the structure of the concepts in the fear spectrum is modified by trait anxiety. In the case of individuals with high level of trait anxiety the structure of the concepts contains excessive information related to the ordinary, trivial causes potentially inducing fear. Conversely, in individuals with low-level trait anxiety, the concepts' structure points to a more objective reality perception which is reflected by little information related to trivial fear causes. Furthermore, individuals with low level of trait anxiety more often indicate well the fictional elements as abstracts or existential aspects. Their word associations with the fear spectrum suggest that they are focused on abstractive elaboration of fear situation. This potentially means that are able to form a cognitive distance from the fear situation.

Limitations The proposed procedure for analyzing qualitative data from emotional verbal fluency technique (EVFT) is a time-consuming method. Moreover, the way of establishing category diversity is partly subjective. As the judges have to analyse the words in terms of their notions/semantic meanings in the categories and compare the categories to finally assess their diversity. We are aware of the inherent subjectivity here, however, to our knowledge, this is the best method available at this time. Next, the conclusions on the emotional concepts differentiation within the fear spectrum refer to the Polish language and also to languages where words fear, anxiety, worry, and panic inherently carry different meanings, e.g. in English.

Future Directions The aim of any future studies will be testing the tendency of other emotional word association and describing other emotion concepts using the verbal fluency techniques. Another important issue is to develop suitable software to support the coding procedure and automatic word count. We used Excel formulas to automatically count words in verbal fluency tasks, however, professional software would help in easier study replication (as for instance in Pennebaker et al. 2015).

\section{Compliance with Ethical Standards}

Conflict of Interest Authors declare that they have no conflict of interest.

Ethical Approval All procedures performed in studies involving human participants were in accordance with the ethical standards of the institutional and/or national research committee and with the 1964 Helsinki declaration and its later amendments or comparable ethical standards.

Informed Consent Informed consent was obtained from all individual participants included in the study.

Open Access This article is licensed under a Creative Commons Attribution 4.0 International License, which permits use, sharing, adaptation, distribution and reproduction in any medium or format, as long as you give appropriate credit to the original author(s) and the source, provide a link to the Creative Commons licence, and indicate if changes were made. The images or other third party material in this article are included in the article's Creative Commons licence, unless indicated otherwise in a credit line to the material. If material is not included in the article's Creative Commons licence and your intended use is not permitted by statutory regulation or exceeds the permitted use, you will need to obtain permission directly from the copyright holder. To view a copy of this licence, visit http://creativecommons.org/licenses/by/4.0/.

\section{References}

Abeare, C. A., Freund, S., Kaploun, K., McAuley, T., \& Dumitrescu, C. (2017). The emotion word fluency test (EWFT): Initial psychometric, validation, and physiological evidence in young adults. Journal of Clinical and Experimental Neuropsychology, 39(8), 738-752. https://doi.org/10.1080/13803395.2016.1259396.

Andrews, M., Frank, S. L., \& Vigliocco, G. (2014). Reconciling embodied and distributional accounts of meaning in language. Topics in Cognitive Science, 6(3), 359-370. https://doi.org/10.1111/tops. 12096.

Apresjan, J. D. (1994). Naiwny obraz świata a leksykografia [Naive picture of the world and lexicography]. Etnolingwistyka, 6, 5-12.

Ardila, A., \& Ostrosky-Solís, F. (2006). Cognitive testing toward the future: The example of semantic verbal fluency (animals). International Journal of Psychology, 41(5), 324-332. https://doi. org/10.1080/00207590500345542.

Barlow, D. H. (2002). Anxiety and its disorders: The nature and treatment of anxiety and panic disorders. New York: Guilford Press. 
Barrett, L. F. (2012). Emotions are real. Emotion, 12, 413-429. https:// doi.org/10.1037/a0027555.

Barrett, L. F. (2013). Psychological construction: A darwinian approach to the science of emotion. Emotion Review, 5, 379-389. https://doi. org/10.1177/1754073913489753.

Barrett, L. F. (2014). The conceptual act theory: A précis. Emotion Review, 6, 292-297. https://doi.org/10.1177/1754073914534479.

Barrett, L. F., Lindquist, K. A., \& Gendron, M. (2007). Language as context for the perception of emotion. Trends in Cognitive Science, 11, 327-332. https://doi.org/10.1016/j.tics.2007.06.003.

Bartczak, M., Szymańska, A., \& Bokus, B. (2010). The word association test: From classic applications to new data. In B. Bokus (Ed.), Studies in the psychology of language and communication (pp. 251-273). Warsaw: Matrix.

Bauman, Z. (2006). Liquid fear. Cambridge: Polity Press.

Berman, S. L., Weems, C. F., \& Stickle, T. R. (2006). Existential anxiety in adolescents: Prevalence, structure, association with psychological symptoms and identity development. Journal of Youth and Adolescence, 35(3), 303-310. https://doi.org/10.1007/s10964-0069032-y.

Berto, G., \& Galaverna, F. S. (2016). Semantic memory organization on verbal fluency test "human body parts" in patients with chronic schizophrenia diagnosis and healthy controls. European Journal of Psychiatry, 30(2), 97-108.

Brzeziński J., Gaul, M., Hornowska, E., Jaworowska, A., Machowski, A., \& Zakrzewska, M. (2004). Skala Inteligencji D. Wechslera dla dorostych. Wersja zrewidowana - renormalizacja WAIS $-R(P L)$ [Manual for WAIS-R, Polish ed.]. Warszawa: PTP.

Cattell, R. B. (1966). The scientific analysis of personality. Chicago: Aldine.

Chan, A. S., Butters, N., Paulsen, J. S., Salmon, D. P., Swenson, M. R., \& Maloney, L. T. (1993). An assessment of the semantic network in patients with Alzheimer's disease. Journal of Cognitive Neuroscience, 5(2), 254-261.

Dąbrowski, K. (1996). Multilevelness of emotional and instinctive functions. Lublin: Towarzystwo Naukowe KUL.

Endler, N. S., \& Kocovski, N. L. (2001). State and trait anxiety revisited. Journal of Anxiety Disorders, 15, 231-245.

Eysenck, M. W. (2012). Fundamentals of cognition (2nd). New York: Taylor and Francis.

Fehr, B. (2005). The role of prototype in interpersonal cognition. In M. W. Baldwin (Ed.), Interpersonal cognition (pp. 180-206). New York, London: Guilford Press.

Frijda, N. H. (2008). The psychologists' point of view. In M. Lewis, J. M. Haviland-Jones, \& L. F. Barret (Eds.), Handbook of emotions (pp. 68-88). New York: The Guilford Press.

Furnham, A., \& Marks, J. (2013). Tolerance of ambiguity: A review of the recent literature. Psychology, 9, 717-728. https://doi.org/10. 4236/psych.2013.49102.

Gawda, B. (2019). The structure of the concepts related to love spectrum. Emotional verbal fluency technique application, initial psychometrics, and its validation. Journal of Psycholinguistic Research, 48(6), 1339-1361. https://doi.org/10.1007/s10936-019-09661-y.

Gawda, B., \& Szepietowska, E. (2013). Impact of unconscious emotional schemata on verbal fluency - Sex differences and neural mechanisms. NeuroQuantology, 11(3), 443-450. https://doi.org/10. 14704/nq.2013.11.3.668.

Gawda, B., \& Szepietowska, E. (2016). Trait anxiety modulates brain activity during performance of verbal fluency tasks. Frontiers in Behavioral Neuroscience, 10, 10. https://doi.org/10.3389/fnbeh. 2016.00010 .

Gawda, B., Szepietowska, E., Soluch, P., \& Wolak, T. (2017). Valence of affective verbal fluency. fMRI studies on neural organization of emotional concepts joy and fear. Journal of Psycholinguistic Research, 46(3), 731-746. https://doi.org/10.1007/s10936-0169462-y.
Goñi, J., Arrondo, G., Sepulcre, J., Martincorena, I., de Mendizábal, N. V., Corominas-Murtra, B. , Villoslada, P. (2011). The semantic organization of the animal category: Evidence fromsemantic verbal fluency and network theory. Cognitive Processing, 12(2), 183196. Doi: Org https://doi.org/10.1007/s10339-010-0372-x.

Harré, R. (1995). Discursive psychology in practice. London: Sage.

Iverach, L., Menzies, R. G., \& Menzies, R. E. (2014). Death anxiety and its role in psychopathology: Reviewing the status of transdiagnostic construct. Clinical Psychology Review, 34, 580-593. https://doi.org/ 10.1016/j.cpr.2014.09.002.

Izard, C. E. (1992). Basic emotions, relations among emotions, and emotion-cognition relations. Psychological Review, 99, 561-565.

Kashdan, T. B., Barrett, L. F., \& McKnight, P. E. (2015). Unpacking emotion differentiation: Transforming unpleasant experience by perceiving distinctions in negativity. Current Directions in Psychological Science, 24, 10-16. https://doi.org/10.1177/ 0963721414550708.

Kępiński, A. (2009). Lęk [Anxiety]. Kraków: Wydawnictwo Literackie.

Kossowska, M. (2005). Umyst niezmienny. Poznawcze mechanizmy sztywności [Rigid mind. Cognitive mechanisms of rigidity]. Kraków: Wydawnictwo UJ.

Kroska, A., \& Goldstone, R. (1996). Dissociations in the similarity and categorization of emotions. Cognition and Emotion, 10(1), 27-45.

Kurcz, I. (1967). Porównanie powszechności skojarzeń w różnojęzycznych grupach studenckich [Comparisons of the universality of associations in multilingual student groups]. Studia Psychologiczne, 8, 256-271.

Lazarus, R. S. (1991). Emotion and adaptation. New York: Oxford University Press.

LeDoux, J. E. (2015). Anxious. Using the brain to understand and treat fear and anxiety. New York: Penguin Books.

Lenci, A., Lebani, G., \& Passaro, L. (2018). The emotions of abstract words: A distributional semantic analysis. Topics in Cognitive Science, 10(3), 550-572. https://doi.org/10.1111/tops.12335.

Lindquist, K. A. (2013). Emotions emerge from more basic psychological ingredients: A modern psychological constructionist model. Emotion Review, 5, 356-368. https://doi.org/10.1177/ 1754073913489750.

May, R. (1950). The meaning of anxiety. New York: W.W. Norton.

Morgan, R. L., \& Heise, D. (1988). Structure of emotions. Social Psychology Quarterly, 51(1), 19-31.

Niedenthal, P. (2008). Emotion concepts. In H. Lewis, J. Haviland-Jones, \& L. Barrett (Eds.), Handbook of emotions (pp. 587-600). New York: Guilford Press.

Niedenthal, P. M., Krauth-Gruber, S., \& Ric, F. (2006). Psychology of emotion: Interpersonal, experiential, and cognitive approaches. New York: Psychology Press.

Oatley, K., \& Johnson-Laird, P. N. (1995). The communicative theory of emotions: Empirical tests, mental models, and implications for social interaction. In L. L. Martin \& A. Tesser (Eds.), Striving and feeling: Interactions among goals, affect, and self-regulation (pp. 363-393). Mahwah: Erlbaum.

Öhman, A. (2008). Fear and anxiety: Overlaps and dissociations. In M. Lewis, J. M. Haviland-Jones, \& L. F. Barret (Eds.), Handbook of psychology (pp. 709-729). New York, London: The Guilford Press.

Öhman, A., Flykt, A., \& Lundqvist, D. (2000). Unconscious emotion: Evolutionary perspectives, psychophysiological data, and neuropsychological mechanisms. In R. Lane \& L. Nadel (Eds.), The cognitive neuroscience of emotion (pp. 296-327). New York: Oxford University Press.

Oosterwijk, S., Touroutoglou, A., \& Lindquist, K. A. (2014). The neuroscience of construction: What neuroimaging can tell us about how the brain creates the mind. In L. F. Barrett \& J. A. Russell (Eds.), The psychological construction of emotion (pp. 11-143). New York: The Guilford Press. 
Pennebaker, J. W., Booth, R. J., Boyd, R. L., \& Francis, M. E. (2015). Linguistic inquiry and word count: LIWC2015. Austin: Pennebaker Conglomerates (www.LIWC.net).

Rachman, S. (2004). Anxiety. Hove: Psychology Press.

Ranschburg, J. (1993). Lęk, gniew, agresja [Fear, anger, aggression]. Warszawa: WSiP.

Riemann, F. (2009). Anxiety: Using depth psychology to find a balance in your life. München: Ernst Reinhardt Verlag.

Robert, P. H., Migneco, V., Marmod, D., Chaix, I., Thauby, S., Benoit, M., Beau, C., \& Darcourt, G. (1997). Verbal fluency in schizophrenia: The role of semantic clustering in category instance generation. European Psychiatry, 12, 121-129.

Rokeach, M. (1960). The open and closed mind. Oxford: Basic Book.

Rossell, S. L. (2006). Category fluency performance in patients with schizophrenia and bipolar disorder: The influence of affective categories. Schizophrenia Research, 82, 135-138. https://doi.org/10. 1016/j.schres.2005.10.013.

Russell, J. A. (1980). A circumplex model of affect. Journal of Personality and Social Psychology, 39, 1161-1178.

Russell, J. A. (1991). Culture and the categorization of emotions. Psychological Bulletin, 11, 426-450.

Russell, J. A. (2005). Emotions and the lexicon. Psychological Inquiry, $16,26-27$.

Russell, J. A., \& Bullock, M. (1986). Fuzzy concepts and the perception of emotion in facial expression. Social Cognition, 4, 309-341.

Russell, W.A. \& Jenkins, J. J. (1954). The Complete Minnesota Norms for responses to 100 words from the Kent-Rosanoff Word Association Test. USN Tech. Rep. No. 11, 1954, ONR N8 ONR 66216, Univ. Minnesota, 1854.

Russell, J. A., \& Lemay, G. (2000). Concepts of emotion. In M. Lewis \& J. Haviland (Eds.), Handbook of emotions (2nd ed., pp. 491-503). New York: Guilford Press.

Russell, W. A., \& Messeck, O. R. (1959). Der Einffluss der Assoziation auf das Erinnern von Worten in der Deutschen, Französischen und Englischen Sprache. Zeitschrift für Experimentelle und Angewandte Psychologie, 6, 191-211.

Russell, J. A., \& Sato, K. (1995). Comparing emotions words between languages. Journal of Cross-Cultural Psychology, 26, 384-391.

Sass, K., Fetz, K., Oetken, S., Habel, U., \& Heim, S. (2013). Emotional verbal fluency: A new task on emotion and executive function interaction. Behavioral Sciences, 3, 372-387. https://doi.org/10.3390/ bs3030372.

Schultz, W., \& Stone, W. (1997). Authoritarianism and mental rigidity. The Einstellung problem revisited. Personal and Social Psychology Bulletin, 23, 3-10.

Schwartz, S., \& Baldo, J. (2001). Distinct patterns of word retrieval in right and left frontal lobe patients: A multidimensional perspective. Neuropsychologia, 39(11), 1209-1217.

Schwartz, S., Baldo, J., Graves, R., \& Brugger, P. (2003). Pervasive influence of semantics in letter and category fluency: A multidimensional approach. Brain and Language, 87, 400-411. https://doi.org/ 10.1016/S0093-934X(03)00141-X.
Shaver, P. R., Schwartz, J., Kirson, D., \& O-Connor, C. (1987). Emotion knowledge: Further exploration of a prototype approach. Journal of Personality and Social Psychology, 52, 1061-1086.

Shaver, P. R., Wu, S., \& Schwartz, J. (1992). Cross-cultural similarities and differences in emotion and its representation: A prototype approach. In M. S. Clark (Ed.), Review of personality and social psychology 13 (pp. 175-212). Newburry Park: Sage.

Sosnowski, T., Wrześniewski, K., Jaworowska, A. i Fecenec, D. (2006). Inwentarz Stanu i Cechy Lęku. Warszawa: Pracownia Testów Psychologicznych PTP [Manual for State Trait Anxiety Inventory, Polish ed.]. Warszawa: PTP.

Spielberger, C. D. (1979). Understanding stress and anxiety. London: Harper and Row.

Spielberger, C. D., Reheiser, E. C., \& Sydema, S. J. (1995). Measuring the experience expression, and control of anger. In H. Kassinove (Ed.), Anger disorders: Definitions, diagnosis, and treatment (pp. 49-67). Washington, DC: Taylor and Francis.

Vigliocco, G., Kousta, S. T., Vinson, D. P., Andrews, M., \& Del Campo, E. (2013). The representation of abstract words: What matters? Reply to Paivio's (2013) comment on Kousta et al. (2011). Journal of Experimental Psychology: General, 142(1), 288-291. https://doi.org/10.1037/a0021446.

Vigliocco, G., Kousta, S. T., Della Rosa, P. A., Vinson, D. P., Tettamanti, M., Devlin, J. T., \& Cappa, S. F. (2014). The neural representation of abstract words: The role of emotion. Cerebral Cortex, 24(7), 1767-1777. https://doi.org/10.1093/cercor/bht025.

Vinson, D. P., Ponari, M., \& Vigliocco, G. (2014). How does emotional content affect lexical processing? Cognition and Emotion, 28(4), 737-746. https://doi.org/10.1080/02699931.2013.851068.

Wauters, L., \& Marquardt, T. P. (2017). Category, letter, and emotional verbal fluency in Spanish-English bilingual speakers: A preliminary report. Archives of Clinical Neuropsychology, 28, 1-14. https://doi. org/10.1093/arclin/acx063.

Wierzbicka, A. (1988). The semantics of emotions: Fear and its relatives in English. Australian Journal of Linguistics, 10(2), 359-375.

Wierzbicka, A. (1992a). Defining emotion concepts. Cognitive Science, 16, 539-581.

Wierzbicka, A. (1992b). Semantics, culture, and cognition. Oxford: Oxford University Press.

Wilson-Mendenhall, C. D., Barrett, L. F., Simmons, W. K., \& Barsalou, L. W. (2011). Grounding emotion in situated conceptualization. Neuropsychologia, 49, 1105-1127. https://doi.org/10.1016/j. neuropsychologia.2010.12.032.

Wilson-Mendenhall, C. D., Barrett, L. F., \& Barsalou, L. W. (2013). Situating emotional experience. Frontiers in Human Neuroscience, 7, 764. https://doi.org/10.3389/fnhum.2013.00764.

Zeidner, M., \& Matthews, G. (2011). Anxiety 101. New York: Springer.

Zimbardo, P. (1990). Shyness. What is it? What to do with it? Boston: Da Capo Press.

Publisher's Note Springer Nature remains neutral with regard to jurisdictional claims in published maps and institutional affiliations. 